This item was submitted to Loughborough's Research Repository by the author.

Items in Figshare are protected by copyright, with all rights reserved, unless otherwise indicated.

\title{
Use of Petri nets to model the maintenance of wind turbines
}

PLEASE CITE THE PUBLISHED VERSION

http://dx.doi.org/10.1002/qre.1737

\section{PUBLISHER}

(c) 2014 John Wiley \& Sons, Ltd

\section{VERSION}

AM (Accepted Manuscript)

\section{PUBLISHER STATEMENT}

This work is made available according to the conditions of the Creative Commons Attribution-NonCommercialNoDerivatives 4.0 International (CC BY-NC-ND 4.0) licence. Full details of this licence are available at: https://creativecommons.org/licenses/by-nc-nd/4.0/

\section{LICENCE}

CC BY-NC-ND 4.0

\section{REPOSITORY RECORD}

Leigh, Johanna M., and Sarah J. Dunnett. 2015. "Use of Petri Nets to Model the Maintenance of Wind Turbines". figshare. https://hdl.handle.net/2134/17253. 
Use of Petri Nets to model the maintenance of wind turbines.

\author{
J.M.Leigh and S.J.Dunnett ${ }^{1}$ \\ Department of Aeronautical and Automotive Engineering \\ Loughborough University \\ Loughborough, Leics. LE11 3TU, U.K. \\ J.M.Leigh@lboro.ac.uk, s.j.dunnett@lboro.ac.uk \\ ${ }^{1}$ Corresponding author
}

\begin{abstract}
With large expansion plans for the offshore wind turbine industry there has never been a greater need for effective operations and maintenance. The two main problems with the current operations and maintenance of an offshore wind turbine are the cost and availability. In this work a simulation model has been produced of the maintenance process for a wind turbine with the aim of developing a procedure that can be used to optimise the process. This initial model considers three types of maintenance; periodic, conditional and corrective and also considers the weather in order to determine the accessibility of the turbine. Petri nets have been designed to simulate each type of maintenance and weather conditions. It has been found that Petri nets are a very good method to model the maintenance process due to their dynamic modelling and adaptability and their ability to test optimisation techniques. Due to their versatility Petri net models are developed for both system hardware and the maintenance processes and these are combined in an efficient and concise manner.
\end{abstract}

Keywords: Petri nets, maintenance, wind turbine

\title{
1. Introduction
}


The maintenance costs associated with any industrial process are generally a significant proportion of the overall running costs. This is particularly true in the case of offshore wind turbines where exposure and accessibility are major factors. For example the cost of maintenance of an offshore wind turbine is $50 \%$ higher than its onshore equivalent, Krohn et $\mathrm{al}^{1}$. In a report by Walford ${ }^{2}$ the relationship between reliability and the costs associated with maintaining a wind turbine and its operation were outlined.

Maintenance consists of replacing, repairing, servicing and modifying components or subsystems, to ensure the entire system is running to a specified capability and availability. The two primary maintenance procedures are preventative and corrective. Preventative is scheduled to occur before the component/subsystem has a chance to fail. In the case of wind turbines this decreases the amount of downtime incurred. Preventative maintenance can be split into two categories which are scheduled periodic and condition based. Corrective maintenance is where failure occurs and then maintenance is used to repair or replace the failed component/subsystem.

Scheduled periodic maintenance takes place at regular intervals based on a plan set out by manufactures or the operators. Parts are replaced when they show signs of wear and therefore they aren't given the chance to fail. Also unrevealed failures, which are failures that can only be seen through inspection, are fixed. The disadvantages of this are that components will not be used to their full lifetime and sufficient planning is required to work around the weather. According to offshore standard DNV-OS-J $101^{3}$ an offshore wind turbine is expected to have a lifetime of 20 years; in these 20 years extensive inspections of the wind turbine are expected at least every five years and general inspections no more than a year apart, typically twice a year. General periodic maintenance, which occurs around every six months, is used to inspect systems and replace deteriorating components to prevent failure. In general the systems considered are the rotor, gearbox, generator, yaw, pitch, electrical and control 
systems. Also lifting appliances and safety equipment are checked. Each is inspected for defaults such as dents and deformations, fatigue cracks, bolt pre-tension and wear. The final stage is re-checking previously outstanding issues. Periodic maintenance should generally take a team of two maintenance engineers around four hours to carry out minor repairs and seven hours for major repairs. For extensive periodic maintenance which occurs approximately every five years, inspection consists of more than the power generation parts. The structural and electrical systems above water, structures below water and submerged power cables also require periodic inspection.

Despite the regular periodic maintenance performed on offshore wind turbines breakdowns still occur leading to corrective maintenance and its resulting downtime. Due to the great distances to the wind turbines to perform any maintenance operators are keen to detect and fix any problem before failure occurs and hence avoid the long downtimes. This has led to the widespread use of condition monitoring on offshore turbines. Condition based maintenance (CBM) means that maintenance is based on the condition of the components and therefore components will be used for a period that is closer to their useful lifetime than in periodic maintenance. Condition monitoring systems (CMS) provide engineers with data regarding turbine parts subject to wear. This results in more informed decision making regarding the maintenance procedures. Due to their use in offshore wind farm maintenance strategies some studies have been conducted on the benefits of CBM in this industry. Nilsson and Bertling ${ }^{4}$ carried out a Life Cycle Cost Analysis to investigate the benefits of CBM and confirmed a reduction in costs. A simulation study of the benefits of CBM was undertaken by McMillan and Ault ${ }^{5}$ using Markov chains and a comparison made between the performance of scheduled maintenance and CBM. A study carried out by Byon et al. ${ }^{6}$ on the simulation of wind farm operations and maintenance shows CBM resulted in higher wind power generation through reducing failure rates and hence increasing availability. However, as well as 
advantages there are also disadvantages of CBM; the systems are expensive, people are required to interpret the output and it can lead to false readings which may lead to the wind turbine being shut down or visited unnecessarily.

Corrective maintenance is carried out when a failure occurs that will affect the turbines performance or is hazardous. This is the simplest to implement but has major disadvantages, as it will create longer periods of down time due to the lead time for new components and waiting for a weather window. Also failure of a small component, which would have been replaced with preventative maintenance, can lead to failure of a major component when left. Corrective is sometimes unavoidable especially with the extreme weather conditions the offshore wind turbines will experience, but should be avoided where possible as it is expensive. Any maintenance required of this nature will warrant revision of the preventative maintenance schedule, decisions will be made based on the trends and patterns of component reliability and failure. A simulation study was undertaken by Rademakers et al $^{7}$ to analyse the operations and maintenance aspects of a case study wind farm. Only corrective maintenance was considered and it was found that the revenue losses due to unavailability were more or less equal to the cost of maintenance.

In order to be able to take full advantage of the benefits that offshore wind turbines can provide the cost of maintenance, due to downtime and maintenance processes, needs to be reduced. This can only be achieved if we can determine the optimal maintenance procedures. One way of doing this is to develop a model of the procedures to investigate their impact. Such a model must be capable of integrating complex component/sub-system behaviour with various maintenance processes and hence Monte Carlo Simulation (MCS) has been adopted. This enables various situations to be considered. Petri Nets (PN's) have been chosen to model both hardware and maintenance processes as they are well suited to modelling dynamic systems where state changes occur at discrete intervals and they also allow for the 
interactions between the hardware and the maintenance processes to be modelled in a simple manner. Due to their strengths and versatility PN's have been adopted to model maintenance in many applications. Yang and $\mathrm{Liu}^{8}$ used them to model predictive maintenance applied to heating and cooling systems. Simeu-Abazi and Sassine ${ }^{9,10}$ adopted PN's to implement various maintenance strategies into a manufacturing system. Bondavalli and Filippini ${ }^{11}$ modelled scheduled maintenance systems. Lei et $\mathrm{al}^{12}$ developed a modularised PN model for manufacturing production line systems integrating corrective and preventative maintenance. Zille et $\mathrm{al}^{13}$ used PN's to assess the performance of multicomponent systems maintained by complex maintenance strategies. Lofstrand et $\mathrm{al}^{14}$ adopted PN's to develop an integrated functional product model encompassing both hardware and support services. Prescott and Andrews ${ }^{15}$ and Andrews ${ }^{16}$ investigated maintenance strategies for the railways using PN's MCS has previously been used to study the effectiveness of various maintenance activities for wind turbines by Andrawus et $\mathrm{al}^{17}$. As PN's have been shown to model hardware performance and maintenance processes efficiently this study has been undertaken in order to investigate the effectiveness of applying these techniques to optimising the maintenance process for offshore wind turbines, As such it is an initial model and can be expanded to include more detail.

\section{Petri Nets.}

Petri nets have been adopted in order to model the dynamics of the maintenance processes and to enable their analysis using MCS. The PN model then allows optimization techniques to be tested before implementing them in real life. A PN is a bipartite directed graph consisting of places and transitions, represented graphically by circles and rectangles respectively. Directed arcs link places to transitions and transitions to places. Places can represent, for example, the state of a component, a maintenance task etc. Transitions can be instant, in which case they are shown as filled rectangles, or have a delay time associated with them which may 
be fixed or determined from a random variable. Tokens, represented by small filled circles, can reside in the places, the distribution of these tokens through the net represents the current state of the system. The tokens move through the net by the firing of the transitions. An example of a PN firing is shown in Figure 1a, in this figure place 1(P1) and place 2(P2) are linked to transition 1(T1) and this transition is linked to place 3(P3). There are 2 links between $\mathrm{P} 1$ and $\mathrm{T} 1$ and this is represented as a weighted edge, weight 2, shown in the net as a dash on the arc with the number 2 next to it. If an arc has no dash on it then it has weight one. When all the input places contain at least the weight number of tokens the transition becomes enabled. Therefore for the transition in Fig. 1a to be enabled P1 must contain at least 2 tokens and P2 must contain at least 1 . The transition has a time delay associated with it. The switching of the transition cannot occur until this delay has elapsed whilst the transition is enabled. Should this delay be zero, then a solid bar would be present, to represent an immediate transition. Once the delay has passed whilst the transition has remained enabled, the switching can occur. The switching process removes 2 tokens from P1 and 1 token from $\mathrm{P} 2$, and a single token is placed in the output place, $\mathrm{P} 3$.

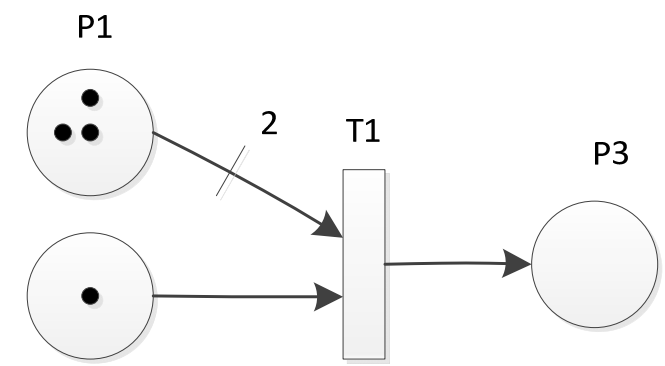

$\mathrm{P} 2$

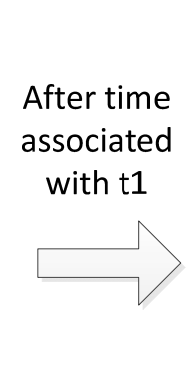

$\mathrm{P} 2$

Figure 1a. Example of Petri Net firing.

It is possible to prevent an enabled transition from firing by using an inhibitor arc, represented by a line with a small open circle on the end. These special arcs only link places 
to transitions. If the number of tokens in the place at the end of the arc is at least that of the arc weighting then the transition to which it is linked cannot not fire regardless of whether it is enabled or not. For example, in Figure 1b, although transition T1 is enabled it cannot fire whilst a token resides in P4.
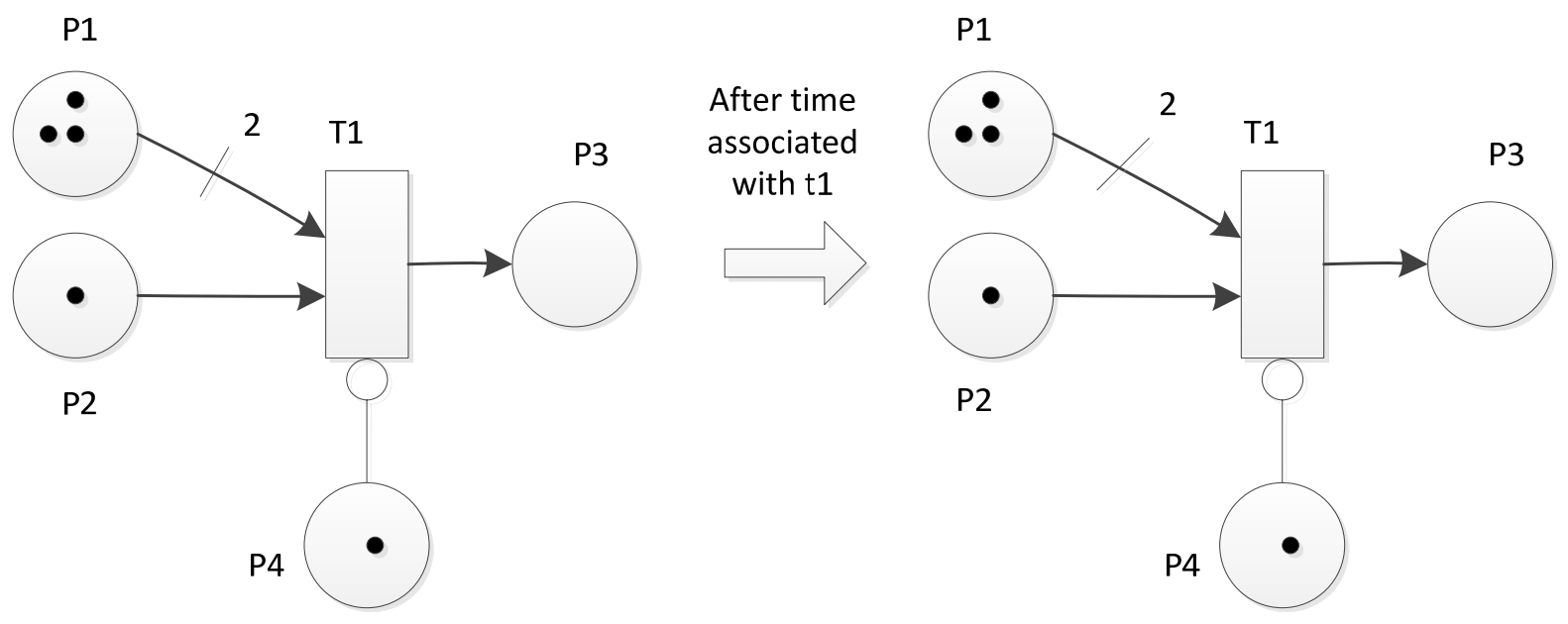

Figure 1b. Example of inhibitor arc preventing firing.

If two arcs point in opposing directions between a place and a transition then they can be combined into a single arc with arrows at both ends.

\section{Model development.}

The aim of this current work is to develop a model of the maintenance procedures for a wind turbine using Petri nets. In order to do this it is necessary to model the states of the systems, subsystems and components and hence a model of the system hardware is required. In this work, as the emphasis is on the maintenance modelling, a detailed model of the system hardware has not been undertaken. The subsystems considered in this paper are the rotor, gearbox, generator, yaw system, pitch system, electrical system and control system. The PN for system failure is shown in Figure 2. 


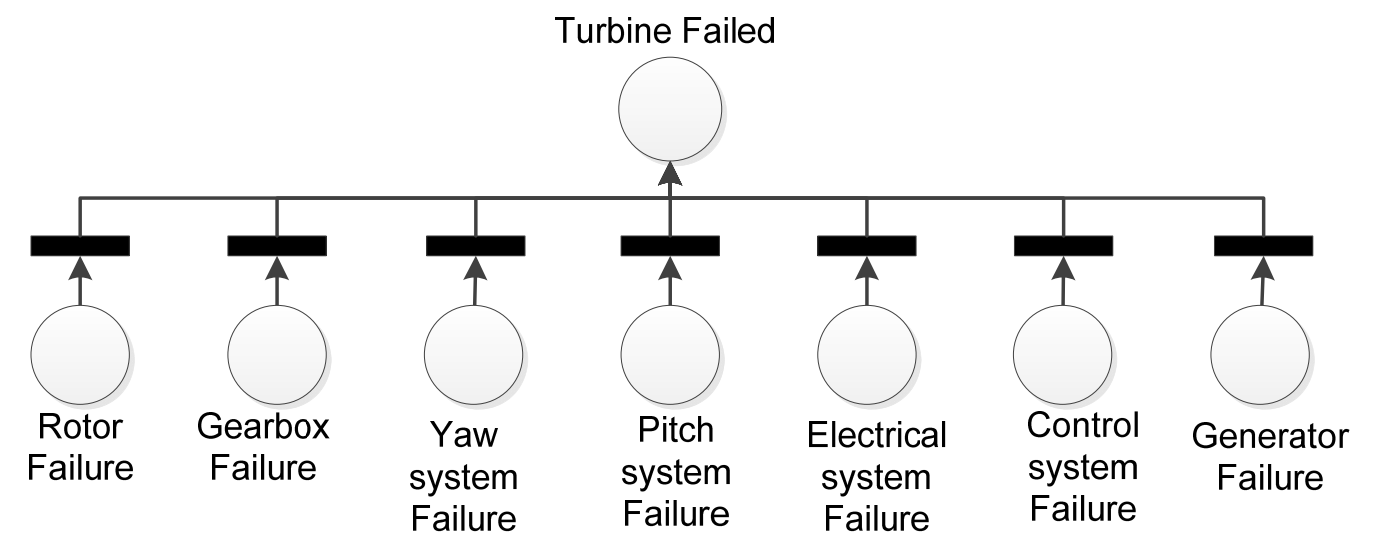

Figure 2. Petri net for system failure

Where appropriate, information regarding subsystem failure and degradation times have been taken from the literature. A general overview of the model developed here, and its connection with a hardware model, is shown in Figure 3 where the area being considered is contained within the blue box labelled maintenance. The hardware model gives information regarding system/subsystem states which determines whether conditional or corrective maintenance needs to take place. After maintenance has taken place the updated information on the states of the components/subsystems is fed back into the hardware model.

The three types of maintenance, periodic, condition based and corrective have been considered and the models developed will be explained separately below. As can be seen in Fig. 3 each type of maintenance consists of obtaining the resources required and then transporting these to the turbine. Due to the location of the turbines, getting these resources where they are needed is very dependent upon the environmental conditions, weather etc. Once on site the appropriate maintenance procedures must be undertaken. Such procedures are a set of tasks, or activities, carried out in a defined order. In this work it is assumed that a maintenance procedure on a particular subsystem will return it to 'as good as new' state. In the model development flow charts were initially developed for each maintenance type, to determine the processes, and these were then transformed into Petri nets. 


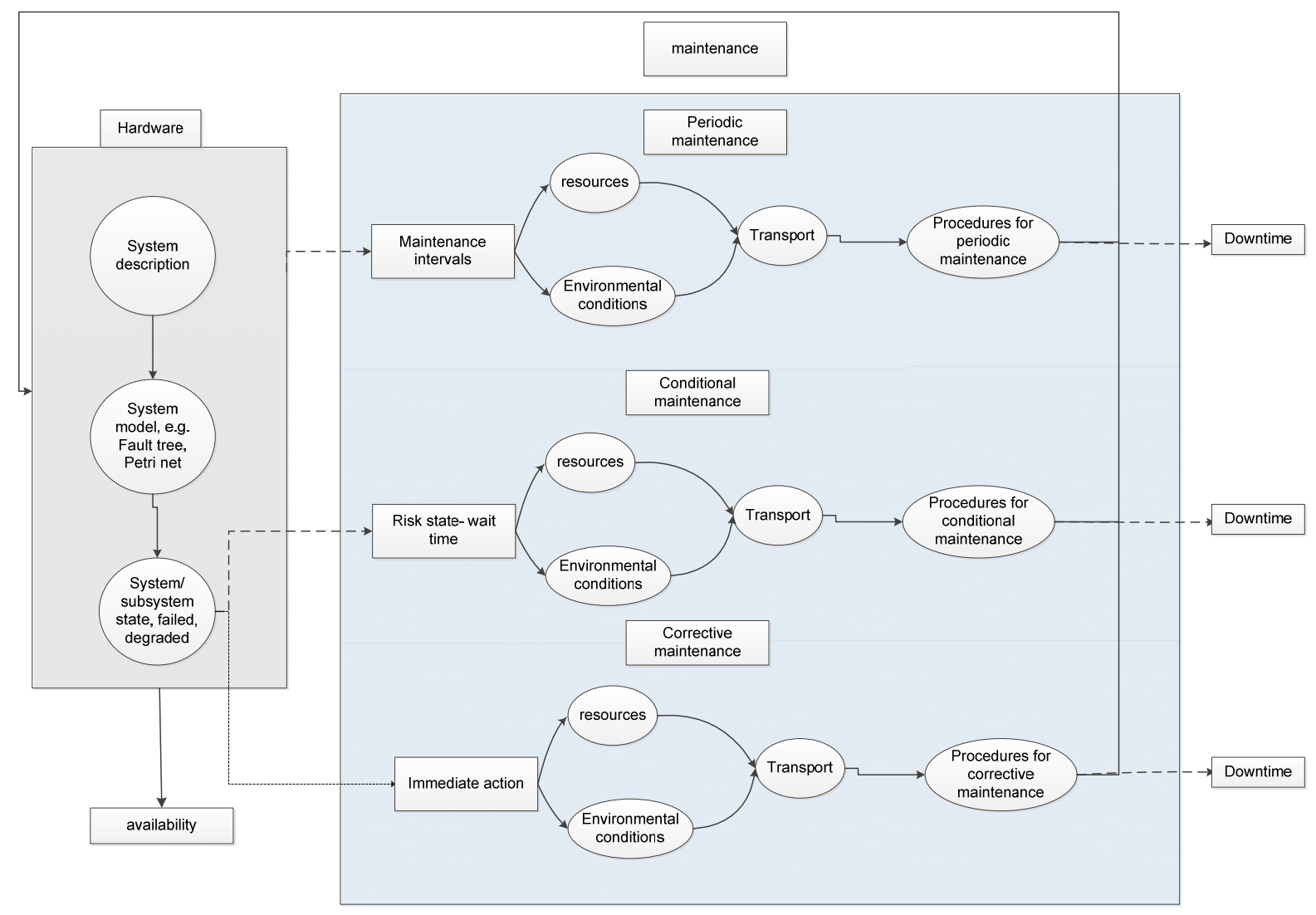

Figure 3. Overview of connection between hardware and maintenance models

A master PN has been developed to model the overall maintenance system, linking together the periodic, conditional and corrective maintenance PN's, this is shown in Figure 4. The individual PN's for the different maintenance strategies are described in detail in the following sections and are represented by dashed boxes in Figure 4. At the appropriate time tokens are fired from the master PN into the individual PN's. The PNs starting point is when the turbine begins its operational lifetime and a token is placed in P1. Tokens will fire instantly into P2-P4 starting the timing for the periodic inspections and also the condition monitoring. Inhibit arcs from P2-P4 to the instant transitions linking them to P1 ensures that tokens are not continually fired. From this point the periodic maintenance is timed to take place every five years for a major inspection and every six months for general inspection, branches 1 and 2 . The weightings $\left(\mathrm{n}_{1}\right.$ and $\mathrm{n}_{2}$ ), on the transitions to the periodic maintenance 
PN's represents the number of maintenance engineers available. This number is variable in order to enable the model to investigate the effects upon turbine downtime and overall cost of allocating different numbers of maintenance engineers. For example, after a time lapse of 6 months the transition on branch 1 will fire and $\mathrm{n}_{1}$ tokens will be placed into $\mathrm{P} 1$ of the periodic maintenance PN shown in Figure 5b. Also the turbine is constantly monitored throughout its life using the CMS, this is represented in the net by placing a token in P4. It has been assumed here, for ease of presentation, that all subsystems considered have CMS, the method outlined could easily be used to model separate CMS on each subsystem. P6 and P7 represent the turbine working and failed respectively, at the start of its life there will be a token in P6 and a transition will be made between the two according to the hardware model, in this case if any of the subsystems fail. 


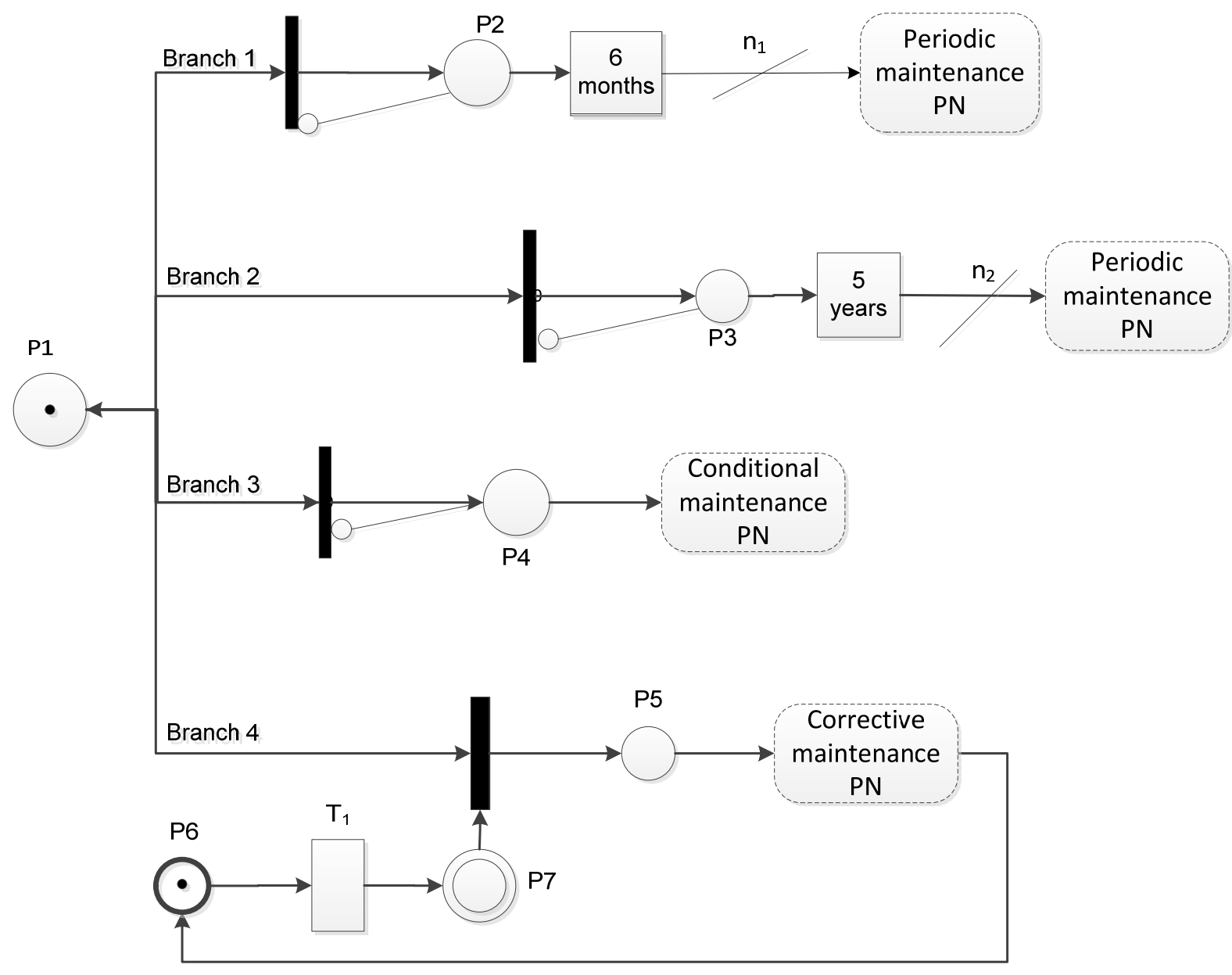

\begin{tabular}{|l|l|}
\hline Notation & What it represents \\
\hline P1 & Turbine operational \\
\hline P2 & Between 6 monthly maintenance \\
\hline P3 & Between 5 yearly maintenance \\
\hline P4 & Turbine under conditional monitoring \\
\hline P5 & Start of corrective maintenance \\
\hline P6 & Turbine working correctly \\
\hline P7 & Turbine failed \\
\hline $\mathrm{T}_{1}$ & Time to system failure. \\
\hline $\mathrm{n}_{1}, \mathrm{n}_{2}$ & Number of maintenance engineers \\
\hline
\end{tabular}

Figure 4. Master Petri Net modelling the overall maintenance procedure.

The 4 branches modelling the 6 month/5 year inspections, conditional and corrective maintenance are described in detail in the following sections.

\section{Periodic maintenance:}


For each of the maintenance periods, 6 months and 5 years, an overall inspection model and system level inspection models have been developed. For both intervals the overall inspection format is the same, it is just the number of systems to be inspected that changes. Figures $5 \mathrm{a}, \mathrm{b}$ show the flow chart and PN respectively for the overall inspection. The times associated with the transitions shown as dashed boxes contained within the dotted rectangle, T5-T11, in fig. $5 \mathrm{~b}$, are the times taken to maintain the subsystems and are obtained from separate system level inspection PN's for each of the subsystems. As stated earlier the difference between the 6 month and 5 year inspections is the number of these subsystems inspected and hence the nets differ by the number of transitions within the dotted rectangle. For clarity of presentation the arc weights have not been included in Fig. $5 \mathrm{~b}$ but all arcs from P1 to T1, T1 to P3, P3 to T2, T2 to P4, P4 to T3, T3 to P5, P5 to T4, T4 to P6, P14 to T13, T13 to P15, P15 to T14, T14 to P16, P16 to T15 and T15 to P17 are of weight $n_{e}$ where $n_{e}$ is the number of engineers sent to perform the maintenance. All other arcs have weight 1 .

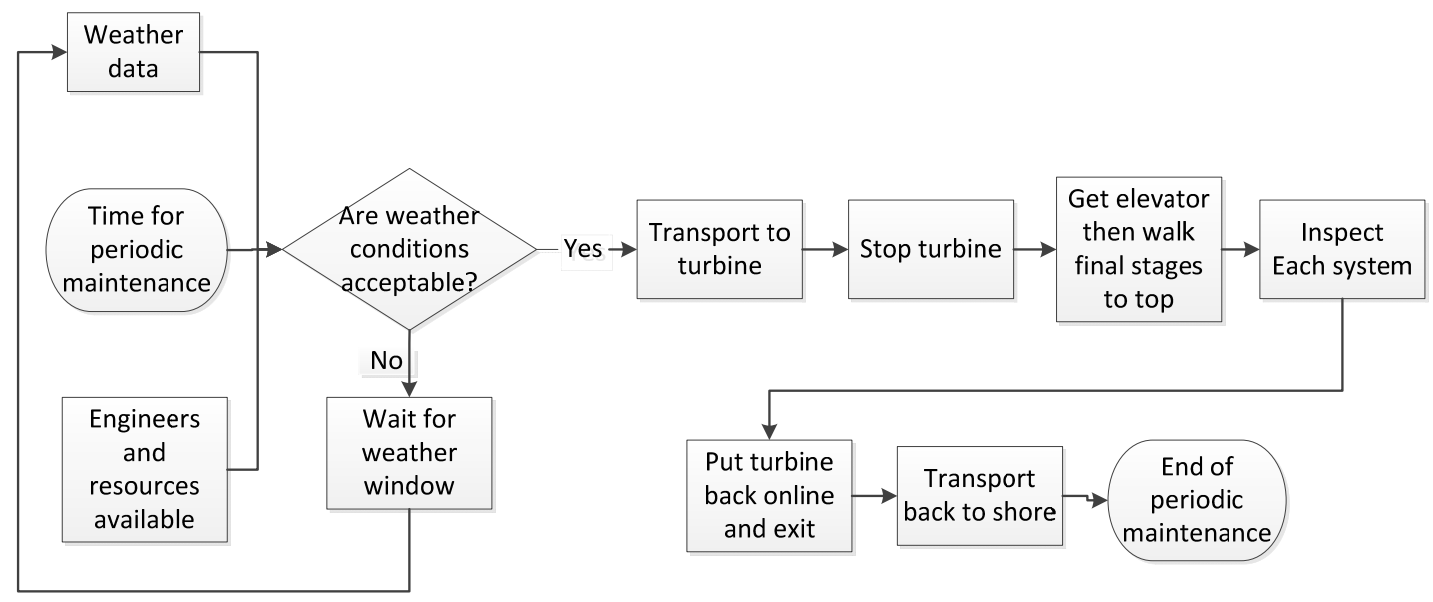

Figure 5a Flow chart for the overall inspection model for periodic maintenance. 


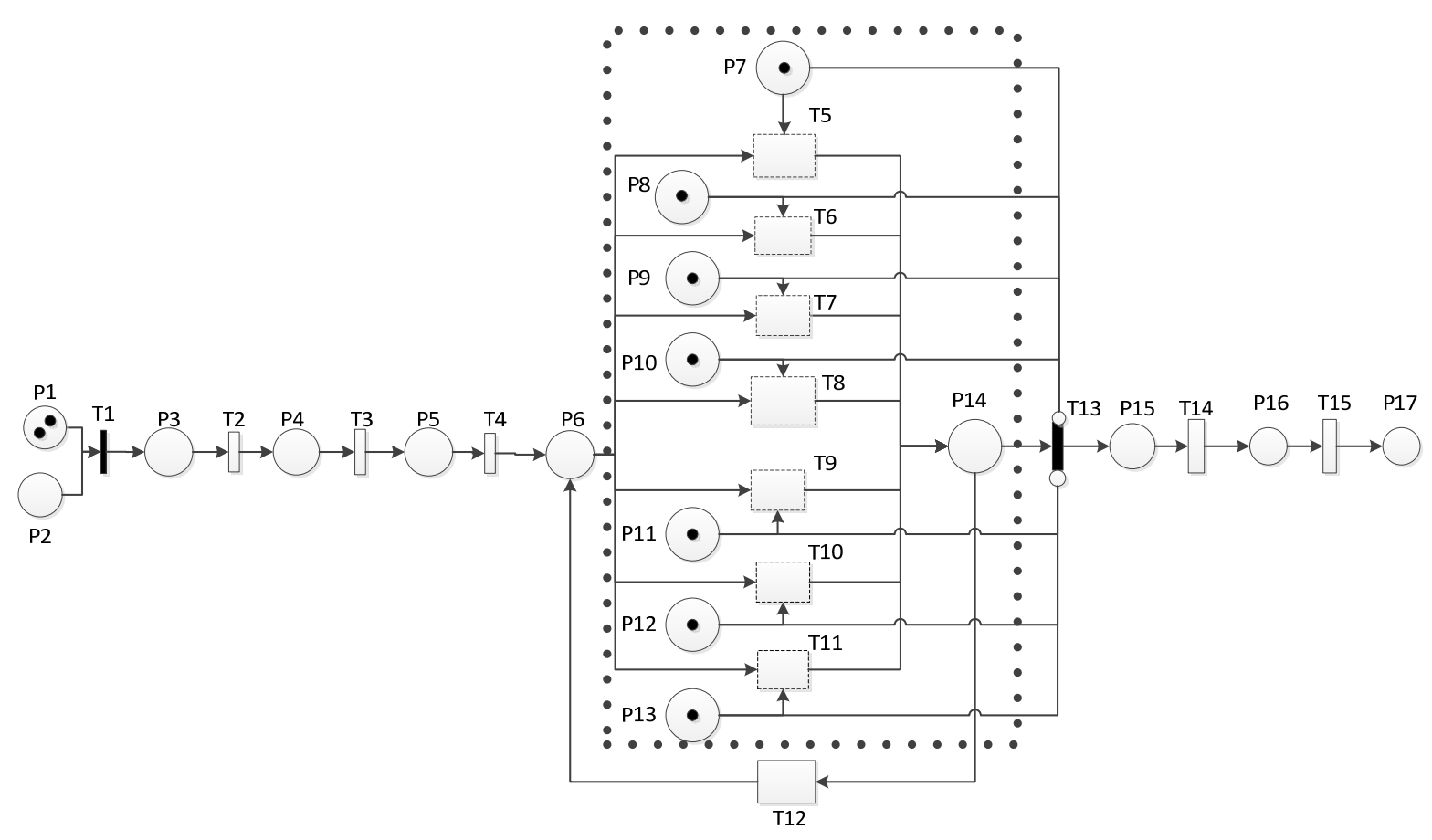

\begin{tabular}{|l|l|}
\hline Place & What it represents \\
\hline P1 & Maintenance engineers available \\
\hline P2 & Acceptable weather \\
\hline P3 & Travel to turbine \\
\hline P4 & At turbine \\
\hline P5 & Turbine shut down \\
\hline P6 & $\begin{array}{l}\text { Maintenance engineer/s at the top waiting to inspect } \\
\text { system }\end{array}$ \\
\hline P7 - P13 & Maintenance of sub-system required \\
\hline P14 & System inspection finished \\
\hline P15 & Put turbine back online and return engineers to base \\
\hline P16 & Travel back to shore \\
\hline P17 & End of periodic maintenance \\
\hline T1 & Maintenance initiated \\
\hline T2 & Time to travel to turbine \\
\hline T3 & Time to shut down turbine \\
\hline T4 & Time to travel to the top of the turbine \\
\hline T5-T11 & Time for system inspections \\
\hline T12 & Time to progress to inspect next system \\
\hline T13 & Maintenance completed \\
\hline T14 & Time to return to transport \\
\hline T15 & Time to return to shore \\
\hline
\end{tabular}

Figure 5b. Petri Net for the overall inspection model for periodic maintenance. 
The initial stages of the PN involve transport to the turbine, turning off the turbine and traveling to the nacelle. After this stage, inspection of the systems commences. The systems to be inspected are the rotor, gearbox, generator, yaw system, pitch system, electrical system and the control system, during extensive maintenance the structure is also inspected. The final stages represent travelling back to shore.

To activate the first transition of this PN the weather must be acceptable and the master PN, Fig. 4, must fire tokens in the initial place P1. The number of tokens deposited from the master PN represents the number of maintenance engineers available. One maintenance engineer is required for each subsystem inspection, therefore subsystem PNs will be running simultaneously if more than one maintenance engineer is available.

The individual subsystem inspection PNs will be activated through the periodic maintenance $\mathrm{PN}$, once a token is in $\mathrm{P} 6$ and the respective subsystem place (P7-P13). An example subsystem level PN is shown in Figure 6. All of the individual subsystems must be inspected before the process can continue, in the PN in fig. $5 \mathrm{~b}$ this is modelled by using inhibit edges to stop transition 13 from firing if any subsystem has not yet been inspected. This will be the case if any of the places P7-P13 contain tokens. In this case any token in P14 due to completed inspection of a subsystem will be fired by T12 back to P6 modelling the availability of a maintenance personnel to inspect another subsystem. Once all subsystems have been inspected the places inhibiting T13 will no longer contain tokens and hence T13 will fire.

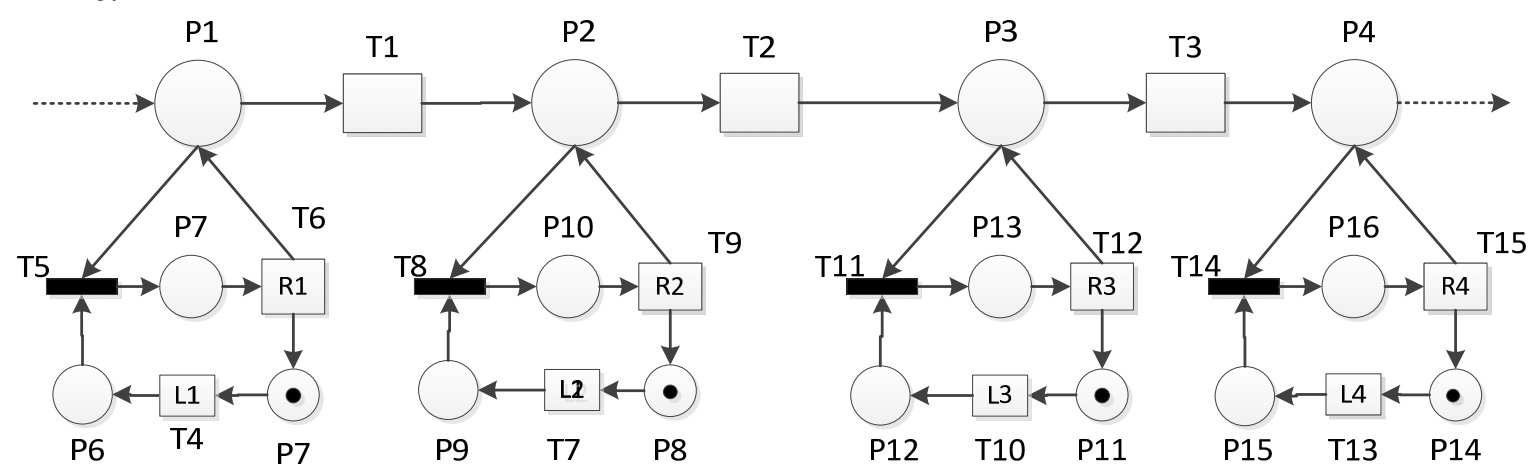




\begin{tabular}{|l|l|}
\hline Notation & What it represents \\
\hline P1 - P4 & Inspection of subsystem/component \\
\hline P5, P8, P11, P14 & Component/subsystem working \\
\hline P6, P9, P12, P15 & Component/subsystem failed \\
\hline P7, P10, P13, P16 & Component/subsystem waiting for repair \\
\hline T1-T3 & Time for engineer to move to next subsystem \\
\hline T4, T7, T10, T13 & Time till subsystem fails \\
\hline T5, T8, T11, T14 & Time until Failure discovered \\
\hline T6, T9, T12, T15 & Time to repair subsystems \\
\hline
\end{tabular}

Figure 6. Petri Net for subsystem inspection

The example subsystem PN in figure 6 involves 4 tasks, represented by P1-P4, each of these involve the inspection and possible repair or replacement of a subsystem or component. For example, in the case of the rotor, P1 would represent the inspection of the surface. Once inspection starts of the rotor a token will be fired into P1 from the periodic maintenance PN, figure 5b. If no damage had occurred to the surface then a token would reside in P5, however if damage has occurred this token will have fired into P6. On inspection T5 will be enabled leading to the removal of tokens from P1 and P6 and the placing of a token in P7 enabling T6. After the time for repair/replacement has elapsed the token will be removed from P7 and one put in P1 and P5 modelling that the component is now in working order and the engineer can move on to inspect the next component, P2. The dotted arcs firing into and out of the net represent the arcs firing into and out of the equivalent subsystem level inspection PN's in Fig. $5 b$.

For the 6 month maintenance the tasks considered here for each of the subsystems inspected are listed in table 1. Obviously this is not an exhaustive list and it is straightforward to add or alter any of the tasks in the nets.

\begin{tabular}{|l|l|}
\hline Subsystem & Task \\
\hline \multirow{4}{*}{ Rotor } & Inspect surface \\
\cline { 2 - 2 } & Check bolts \\
\cline { 2 - 2 } & Check joint seals \\
\cline { 2 - 2 } & Inspect lightning protection system \\
\hline \multirow{4}{*}{ Gearbox } & Check for oil contamination \\
\cline { 2 - 2 } & Check oil level \\
\cline { 2 - 2 } & Check gear, gear stay, bushings and toque arm condition \\
\hline
\end{tabular}




\begin{tabular}{|l|l|}
\hline \multirow{4}{*}{ Generator } & Check gearbox and oil line cooling system \\
\cline { 2 - 2 } & Inspect visible bearings, cogs etc. \\
\cline { 2 - 2 } & Check for oil contamination \\
\cline { 2 - 2 } & Check oil level \\
\cline { 2 - 2 } & Check slip ring integrity \\
\cline { 2 - 2 } Yaw & Check cooling system \\
\hline \multirow{5}{*}{$\begin{array}{l}\text { Pystem } \\
\text { system }\end{array}$} & Check cable \\
\cline { 2 - 2 } & Check motor function \\
\cline { 2 - 2 } Electrical & Check brake pads \\
\cline { 2 - 2 } system & Check lubrication of bearing \\
\cline { 2 - 2 } & Check motor function \\
\cline { 2 - 2 } & Check componenent integrity \\
\cline { 2 - 2 } & Check component functionality \\
\hline Controller & Calibration integrity \\
\cline { 2 - 2 } & Operation of emergency shut down \\
\cline { 2 - 2 } & Operation of SCADA \\
\hline
\end{tabular}

Table 1. Tasks considered in 6 month periodic maintenance.

\section{Conditional maintenance}

The rotor, gearbox, generator, yaw system, pitch system, electrical system and control system are all monitored. This monitoring detects system faults where the system hasn't failed yet but is showing signs of wear or damage. When a fault is detected it is presumed the system requires replacing, hence a new system is ordered. In this work it is assumed that the CMS's are perfectly reliable and do not give any false results. The method outlined here could be adapted to include these. Conditional maintenance is not instantly required, once the fault or degradation is detected it is possible for the system to remain working. It is not cost effective to replace the component instantly as it can still function until closer to its end of life. This decreases replacement costs and allows the turbine to continue running during the component lead time. The time the system can be left running, known as the wait time, can be determined by analysing the risk the system failing possesses to the turbines functionality. Risk is defined as the product of the probability, or frequency, and consequence of an event. In this case the events are the systems failing and the consequences are the cost of system 
replacement. In this work the data used is shown in Table 2 taken from The Crown Estate ${ }^{18}$ and Van Bussel and Zaaijer ${ }^{19}$.

\begin{tabular}{|l|c|c|}
\hline System & Failure frequency (/year) & Cost \\
\hline Rotor & 0.16 & $£ 1,200,000$ \\
\hline Gearbox & 0.3 & $£ 700,000$ \\
\hline Generator & 0.05 & $£ 200,000$ \\
\hline Yaw & 0.23 & $£ 100,000$ \\
\hline Pitch & 0.28 & $£ 100,000$ \\
\hline Electrical & 0.14 & $£ 10,000$ \\
\hline Control & 0.34 & $£ 70,000$ \\
\hline
\end{tabular}

Table 2. Failure frequency and replacement cost for subsystems considered

The risk categories and the associated wait times have been taken from the work of McMillan and Ault ${ }^{5}$, see table 3 .

\begin{tabular}{|l|c|c|}
\hline Risk classification & Risk & Wait time (days) \\
\hline Low & Risk $<£ 1000$ & 140 \\
\hline Medium & $£ 1000 \leq$ risk $\leq £ 4000$ & 28 \\
\hline High & Risk $>£ 4000$ & 7 \\
\hline
\end{tabular}

Table 3. Risk categories and associated wait times

The low risk components have a long wait time meaning that they may fall within a scheduled maintenance slot. If the lead time is longer than the wait time the maintenance will then be corrective maintenance. The PN used to simulate conditional maintenance for subsystem $i$ is shown in Figure 7. All subsystems have nets of the same structure and they connect with each other as shown for 2 nets, $\mathrm{i}$ and $\mathrm{j}$, in Figure 7. 


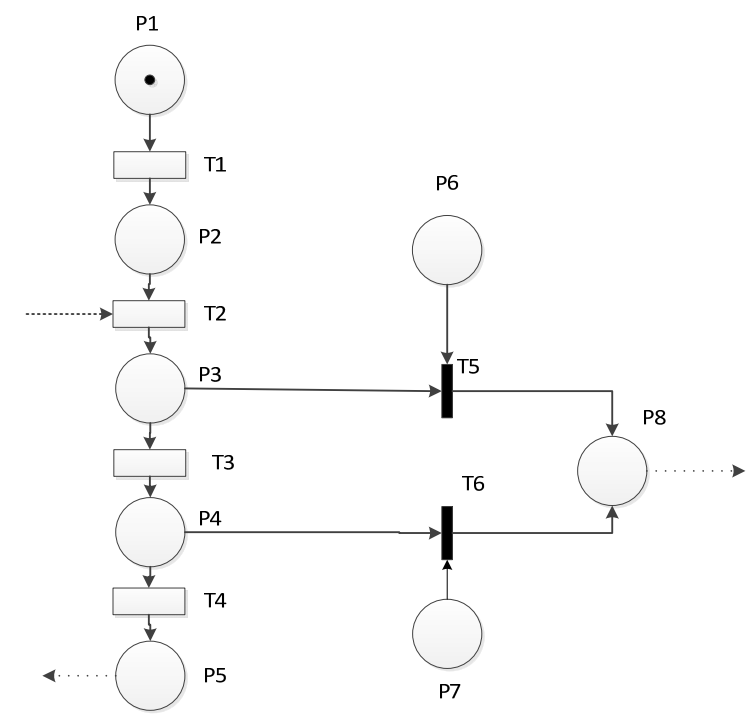

\begin{tabular}{|l|l|}
\hline Notation & What it represents \\
\hline P1 & Subsystem i working \\
\hline P2 & Subsystem i degraded \\
\hline P3 & Subsystem i in wait time \\
\hline P4 & Subsystem i to be repaired \\
\hline P5 & Subsystem i repaired \\
\hline P6 & Subsystem $j$ to be repaired (in PN for j) \\
\hline P7 & Subsystem $\mathrm{j}$ in wait time (in PN for j) \\
\hline P8 & Subsystem $i$ and j to be repaired \\
\hline T1 & Time to Subsystem i degraded. \\
\hline T2 & Time to source replacement part \\
\hline T3 & Wait time for subsystem i. \\
\hline T4 & Time for repair of subsystem i. \\
\hline T5 & Subsystem i taken out of wait time \\
\hline T6 & Subsystem $\mathrm{j}$ taken out of wait time \\
\hline
\end{tabular}

Figure 7. Petri net for conditional maintenance for subsystem $i$.

P1 represents the subsystem working, at the start of the turbines life a token will reside in this place for all subsystems, after a time represented by transition T1 this subsystem degrades. If there is a CMS operating, which would be represented by a token in P4 in the master PN, Fig. 4, and connected by the dotted arc in Fig. 7, then a replacement would be ordered and hence there is a time delay represented by $\mathrm{T} 2$ before the part is available. A wait time is generated from the risk posed by the subsystem failure before replacement in the turbine is performed. This is represented by T3 in Figure 7. If another subsystem is being replaced during this wait time then the replacement of subsystem $\mathrm{i}$ is bought forward as maintenance crew are 
travelling to the turbine. This is represented by $\mathrm{T} 5$ in the figure. If no other subsystem is replaced then after the delay associated with $\mathrm{T} 3$ has elapsed a maintenance crew will travel to the turbine when weather allows and replace the subsystem, time associated with this, T4. If at this point another system is in its wait time that will also be replaced. After the subsystems are replaced they are considered as good as new in the hardware model, hence the dotted arrows from places P5 and P8 feed into the hardware model.

\section{Corrective maintenance}

Corrective maintenance will occur when a system is down, the PN modelling this for one subsystem is shown in Figure 8. The structure of the nets is the same for all the subsystems, it is just the times associated with the transitions that changes. When a token is in a subsystem down place, P2, this feeds into the hardware model, Fig. 2. If this results in a turbine failure then a token will move out of P6 and into P7 in the master PN, Fig. 4. This will result in a token firing into P5 in the master PN which is linked to T2 in Fig. 8. This enables the transition and hence starts the lead time due to the sourcing of the necessary parts, vessel and maintenance. There will be long delays at the start of the process to source the necessary parts, vessel and maintenance engineers as well as waiting for an appropriate weather window, which all contributes to downtime. After this time has elapsed a token will be fired into P3 representing that the subsystem is under repair. After the time associated with repair, T3, has elapsed a token will fire into P1 and also information is sent back into the hardware model to reset the token position to the subsystem working position. 


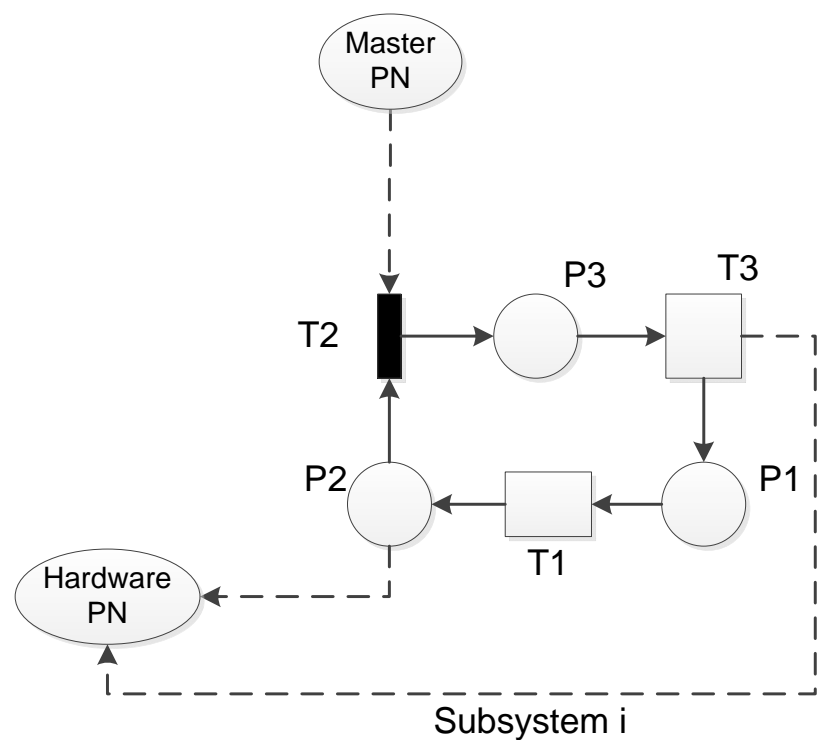

\begin{tabular}{|l|l|}
\hline Notation & What it represents \\
\hline P1 & Subsystem working \\
\hline P2 & Subsystem failed \\
\hline P3 & Subsystem under repair \\
\hline T1 & Time to Subsystem failure \\
\hline T2 & $\begin{array}{l}\text { Start repair if subsystem failure } \\
\text { leads to turbine failure }\end{array}$ \\
\hline T3 & Time to repair Subsystem \\
\hline
\end{tabular}

Figure 8. Petri Net for corrective maintenance of a subsystem

Whenever maintenance has to be performed the weather conditions have to be checked to see if access to the turbine is possible. A PN has been developed that considers the conditions in the 4 seasons, using data from the literature. The weather PN is linked to each PN where access to a turbine is required. This PN will consider the probability of changing between good and bad weather depending on the season; therefore simulating weather windows. When an appropriate weather window is available a marker will be added in the places in other PNs, where required. These will be removed when an appropriate window is not available. The two key weather aspects to be considered are the wave height and wind speed.

In order to run the model, information regarding subsystem and component times to failure, time for maintenance task completion, component repair and weather data must be input. In the case of the subsystems and components it has been assumed that their failure follows a 
Weibull distribution and where possible the parameters have been taken from the literature, Tian et $\mathrm{al}^{20}$. For those not found in the literature the parameters have been estimated through their similarity to components for which data is available. The times for maintenance task completion and component repair have also been taken from the literature, Kovacs et $\mathrm{al}^{21}$ where possible. In the case of weather data the wind speed is used to determine whether access is possible. This is predicted using Weibull parameters taken from Chang et $\mathrm{al}^{22}$. The probability of high wind speed throughout the year is not constant. In winter and autumn wind speeds are generally high and therefore the seasons must be accounted for in the simulation. This is done through using different lifetime parameters depending on the season. It is assumed that the turbine is inaccessible if the wind speed is over $10 \mathrm{~m} / \mathrm{s}$. Periodic and conditional maintenance can then be scheduled when good weather is available. Corrective maintenance is postponed until good weather is available.

The transport used to carry out the maintenance is assumed to be a boat. The average distance to an offshore wind turbine is taken to be $23.4 \mathrm{~km}$ ( Tian et $\mathrm{al}^{20}$ ) and the average speed the type of transport required travels at is $11.1 \mathrm{~km} / \mathrm{h}$ hence the time to reach the turbine is taken to be around 2.1 hours. To hire a vessel for a day the charge is $£ 1,500 /$ day, or a vessel can be brought for around $£ 1.5$ million.

The performance of a turbine over its lifetime has been simulated using the PN's described in the previous section, where a lifetime is taken to be 20 years. The times for each transition that are governed by a distribution are randomly sampled using the method described in Andrews and $\operatorname{Moss}^{23}$. The simulation algorithm for $\mathrm{n}_{\mathrm{S}}$ simulations contains the following steps:

1. Place tokens in place 1 of the overall maintenance PN shown in Fig. 4 and the relevant season in the weather PN. 
2. Randomly sample failure and repair times.

3. Determine the earliest timed transition to switch in the overall maintenance PN, fig. 4, and fire it.

4. Activate the relevant maintenance $\mathrm{PN}$ associated with the transition fired in previous step (Periodic, conditional or corrective)

5. Record downtime from maintenance PN.

6. Randomly sample new failure and repair times associated with maintenance PN.

7. Check overall maintenance PN for next time transition to switch and fire it. Repeat steps 4-6

8. Repeat step 7 until the lifetime of the turbine is reached.

9. Repeat steps 1-8 until $\mathrm{n}_{\mathrm{S}}$ simulations have been performed.

\section{Results}

A program implementing the methods outline in the above section has been produced and the results from this can be used to optimise the maintenance process. Initially a study was made into the number of lifetime simulations $\left(\mathrm{n}_{\mathrm{S}}\right)$ required for convergence, the results from this study are shown in Figure 9 where the average downtime of the turbine in hours as a function of $\mathrm{n}_{\mathrm{S}}$ is shown. As can be seen the results converge within approximately 1000 simulations. Any further simulations do not affect the results by more than $2 \%$. Hence all further results contained within this paper have been obtained after 1000 simulations. In Figure 10 the number of times corrective maintenance is required for each system is shown. The gearbox shows the highest number followed by the generator this trend was also found when considering conditional maintenance. This verifies the statement in the literature review which refers to the gearbox and generator having the highest failure rates, McMillan and Ault 5 . 


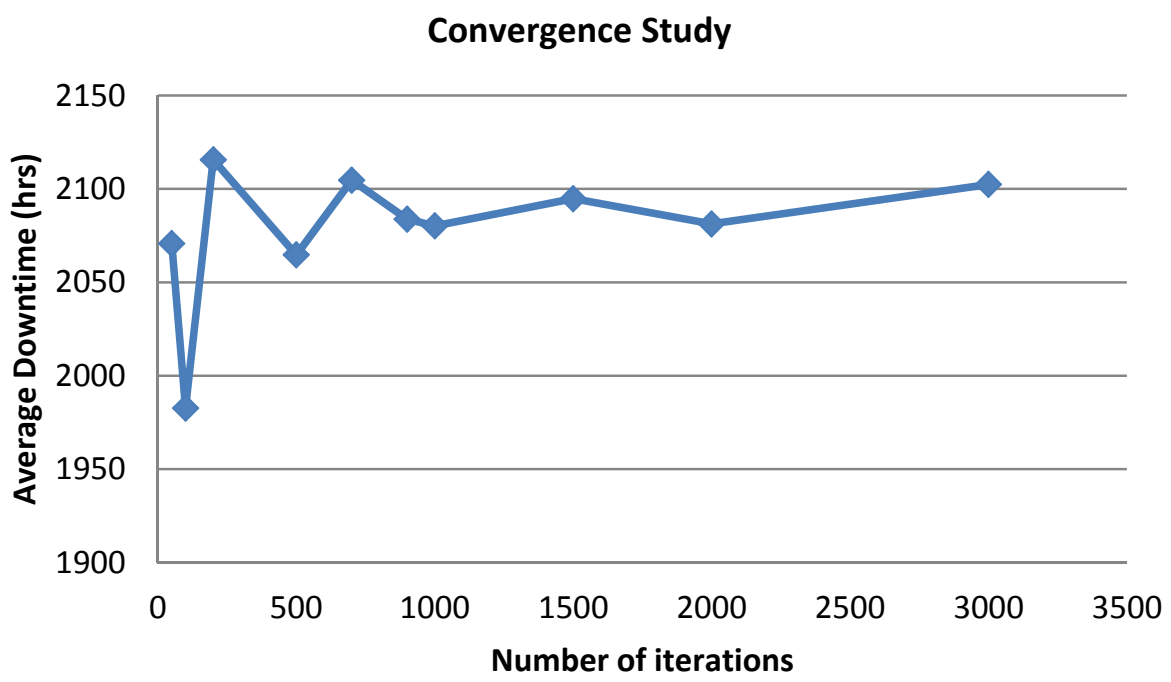

Figure 9. Average downtime as a function of number of simulations

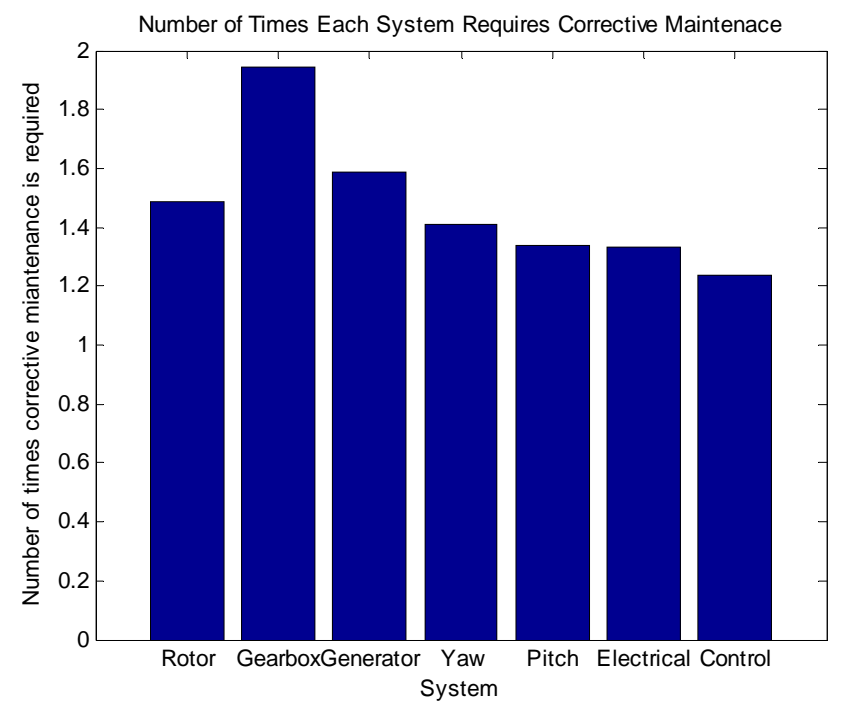

Figure 10. Number of times corrective maintenance is required for each subsystem.

Once the model has been developed it is straightforward to investigate the effects of changing various aspects of the maintenance process with the aim of increasing availability and decreasing cost of the turbine maintenance. Availability relates to the downtime, this is decreased by both increasing the frequency and quality of the maintenance, this however does increase maintenance costs. The logistics, scheduling of engineers and availability of spare parts, is an area which could allow improvement. 
Considering periodic maintenance, this occurs at set intervals of time, involves many routine tasks and is planned well in advance. It is possible for a number of engineers to perform this maintenance. The maximum number is obviously constrained by transport and space within the turbine. The method developed here allows for the downtime due to periodic maintenance to be determined for different numbers of available engineers. The downtime measured for this instance is the time which the turbine is shut down whilst periodic maintenance takes place. The cost of the engineers + downtime can then be determined. In this work it has been assumed that the cost per hour for each engineer is $£ 50$ and the lost revenue due to downtime is given by equation (1) McMillan and Ault ${ }^{5}$.

\section{Effect of increasing number of engineers on cost}

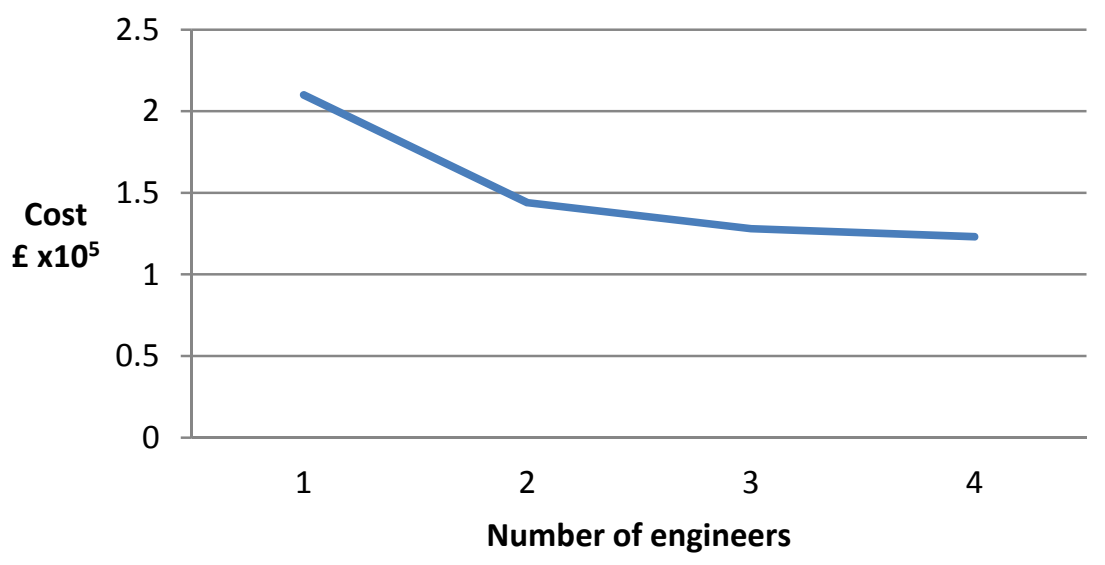

Figure 11. Cost of periodic maintenance as a function on number of engineers.

$L R=P \times C F \times m \times d t$

Where LR is lost revenue due to downtime, $\mathrm{P}$ is turbine power in $\mathrm{Kw} / \mathrm{h}, \mathrm{CF}$ is a capacity factor, $\mathrm{m}$ is the profit per $\mathrm{kW}$ and $\mathrm{dt}$ is the downtime. In this work $\mathrm{P}$ is taken as $5 \mathrm{MW}, \mathrm{CF}$ as 0.4 and $\mathrm{m}$ as $7 \mathrm{p}$. Figure 11 shows the total cost of engineers + downtime for periodic maintenance for 1-4 engineers. It can be seen that the effect of increasing the number of 
engineers decreases as the number increases, this is because the savings made in the reduction of downtime become close to the costs of the extra engineers.

To analyse which spare parts are cost effective to store, the result of storing different systems has been considered. The gearbox fails most frequently and causes one of the longest periods of downtime (DT) hence storing a gearbox will decrease the costs incurred through downtime more than other systems, due to this the effects of storing a gearbox on its own will be considered. Storing the gearbox and generator will also be considered as the generator has the second highest failure rate. The effects of storing a spare for every system have also been considered. Included in the figures is the cost of storing the parts.

\begin{tabular}{|l|c|c|c|c|}
\hline Spare Parts & DT (hrs) & $\begin{array}{c}\text { System } \\
\text { Availability } \\
\mathbf{( \% )}\end{array}$ & Cost of DT (£) & System cost (£) \\
\hline No spare parts & 6,255 & 96.4 & 876,000 & $7,658,000$ \\
\hline 1x Gearbox & 4,268 & 97.6 & 597,000 & $8,193,000$ \\
\hline 1xGearbox, 1x Generator & 3,132 & 98.2 & 439,000 & $8,438,000$ \\
\hline 1x every system & 676 & 99.6 & 95,000 & $10,068,000$ \\
\hline
\end{tabular}

Table 4: The variation in cost and DT with the number of spare parts available

Table 4 shows the results of storing spare parts. These measurements are taken over the turbines lifetime. The DT is the total time the turbine is shut down over this period. System availability is the percentage of time the turbine can be used over this period. Cost of DT is the lost revenue due to the turbine being in downtime. System cost is the total amount spent on replacement and spare systems over this period.

When spare parts are stored there is a significant decrease in downtime and the associated lost production costs, as the lead times due to ordering and obtaining failed parts are removed. The availability of the turbine has increased from $96.4 \%$ to $99.6 \%$. As expected the system cost has increased as more subsystems are purchased than are used. When no spare parts are 
stored then subsystems are purchased when necessary, if every subsystem has a spare stored then there is a duplicate of subsystems. The operator must make the compromise between availability and cost. This compromise may involve only storing key systems such as a gearbox and generator, which are shown to give significant increases in a availability whilst keeping costs lower than storing every system.

Different types of maintenance cause different problems, using periodic and conditional based maintenance means systems are replaced before failure and corrective maintenance suffers from long periods of downtime. The model developed here can be used to investigate each type of maintenance to see what is cost effective to apply.

Considering periodic maintenance, if each subsystem was to be replaced in the five year extensive maintenance plan this would reduce the amount of corrective and conditional maintenance required. It has been found from the model that each system is replaced between 2.5 and 3.9 times in a lifetime. Replacing each subsystem every 5 years would result in each subsystem being replaced at least 3 times in the turbines lifetime. Figure 12 shows how the average number of occurrences of corrective maintenance decreases when the systems are replaced every five years.

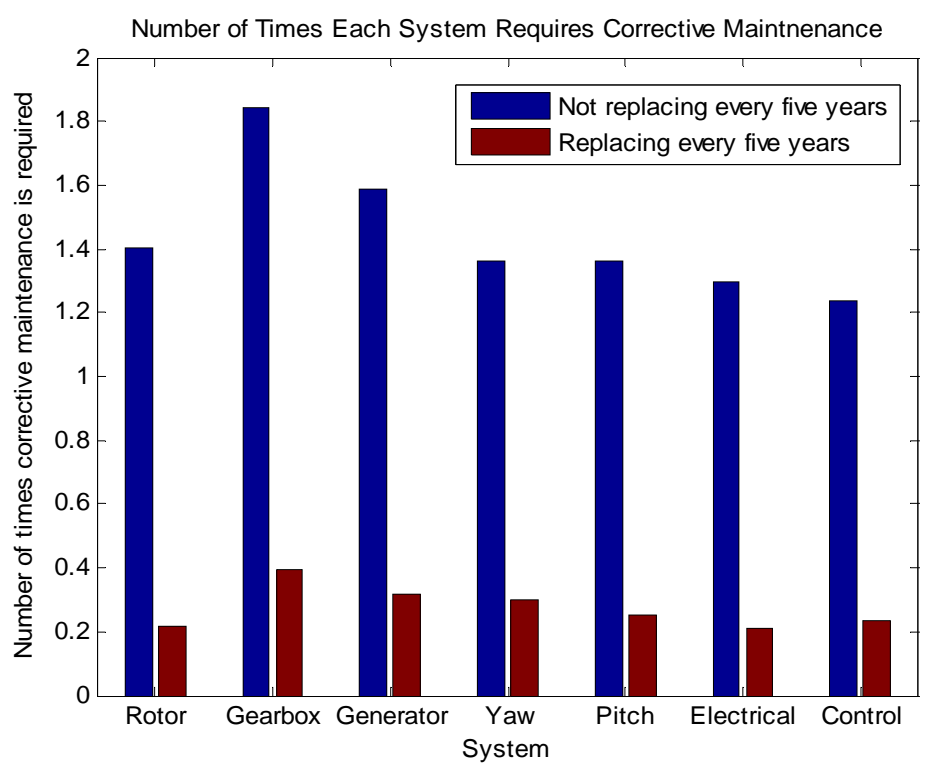


Figure 12. Effects on corrective maintenance of replacing each subsystem.

\section{Conclusions}

This paper has outlined the development of a mathematical model to simulate an optimised maintenance plan for an offshore wind turbine. This included three types of maintenance; periodic, conditional and corrective maintenance as well as simulating weather windows through predicting wind speed. The primary outcomes of this simulation are failure data, the downtime and cost of running a wind turbine for a lifetime of 20 years. The aim of the study has been to develop a model using Petri Nets and to determine the feasibility of adopting this technique to efficiently model the maintenance processes. There are many areas within the model where more detail could be taken and the nets extended but the basic structure of the nets would remain the same. The model can easily be adapted for use on different wind turbines and wind farms. Possible adaptations include the number of systems and tasks involved in each type of maintenance, which means that it can be applied to different turbine designs.

It has been shown that Petri Nets are a very efficient means of modelling the maintenance of turbines and are very adaptable. The use of the nets makes the software implementation of the model straightforward and results have been obtained that demonstrate the models ability to provide useful information.

\section{References}

1. Krohn, S., Morthorst, P-E.,Awerbuch, S. Economics of Wind Energy. Report of The European Wind Energy Association, 2009. 
2. Walford, C. Wind Turbine Reliability: Understanding and Minimizing Wind Turbine Operation and Maintenance Costs, Sandia Report 2006, SAND2006-1100, DOI: $10.2172 / 882048$

3. DNV-OS-J101 (2011), DNV Standard on Design of Offshore Wind Turbine Structures, http://www.dnvkema.com/services/ces/wind-energy/standardsguidelines.aspx [Feb. 2013]

4. Nisson, J. and Bertling, L. Maintenance management of wind power systems using condition monitoring system - life cycle cost analysis for two case studies, IEEE Transactions on Energy Conversion, 2007, 22, 223-229.

5. McMillan, D. and Ault, G.W. Quantification of condition monitoring benefit for offshore wind turbines, Wind Engineering, 2007, 31, 267

6. Byon, E., Perez, E., Ding, Y. and Ntaimo, L. Simulation of wind farm operations and maintenance using discrete event system specification, Simulation-transactions of the society for modelling and simulation international, 2011, 87,1093-1117.

7. Rademakers, L.W.M.M., Braam, H., Zaaijer, M.B. and Van Bussel, G.J.W. Assessment and optimisation of operation and maintenance of offshore wind turbines, Technical Report, 2003, https://www.ecn.nl/publications/WIN/2003/ECN-RX--03$\underline{044}$ [Feb. 2013]

8. Yang, S.K. and Liu, T.S. A Petri Net Approach to Early Failure Detection and Isolation for Preventative Maintenance, Quality and Reliability Engineering International 1998, 14, 319-330.

9. Simeu-Abazi, Z. and Sassine, C. Maintenance integration in manufacturing systems by using stochastic Petri nets, International Journal of Production Research 1999, 37 , $3927-3940$ 
10. Simeu-Abazi, Z. and Sassine, C. Maintenance integration in manufacturing systems: from the modelling tool to evaluation, International Journal of Flexible Manufacturing Systems 2001, 13, 267-285.

11. Bondavalli, A. and Filippini, R. Modeling and analysis of a scheduled maintenance system; a DSPN approach, The Computer Journal 2004, 47, 634-650.

12. Lei, Y., Liu, J., Ni, J. and Lee, J. Production line simulation using STPN for maintenance scheduling, Journal of Intelligent Manufacturing 2010, 21, 213-221.

13. Zille, V., Berenguer, C., Grall, A. and Despujols, A. Modelling multicomponent systems to quantify reliability centred maintenance strategies, Proceedings of the Institution of Mechanical Engineers, Part O 2011, 225, 141-160. DOI:

$10.1177 / 1748006 \times 11402269$

14. Lofstrand, M., Reed, S., Karlberg, M., Andrews, J. Karlsson, L. and Dunnett, S. Modelling and simulation of functional product system availability and support costs, International Journal of Product Development 2012, 16, 304-325.

15. Prescott, D. and Andrews, J. A track ballast maintenance and inspection model for a rail network, Proceedings of the Institution of Mechanical Engineers, Part O 2013, $227,251-266$.

16. Andrews, J. A modelling approach to railway track asset management, Proceedings of the Institution of Mechanical Engineers, Part F 2012, 227, 56-73.

17. Andrawus, J., Watson, J. and Kishk, M. Wind Turbine Maintenance Optimisation: principles of quantitative maintenance optimisation, Wind Engineering 2007, 31, 101110

18. The Crown Estate Offshore Wind Cost Reduction Pathways Study. London : The Crown Estate 2012. http://www.thecrownestate.co.uk/media/305094/ei-offshorewind-cost-reduction-pathways-study.pdf [Jan. 2013] 
19. Van Bussel, G.J.W. and Zaaijer, M.B. Reliability, Availability and Maintenance aspects of large-scale offshore wind farms a concept study. :Proceedings of MAREC 2001 Marine Renewable Energies Conference, Newcastle U.K. 2001, IMarE conference Vol: 113, 119-126

20. Tian, Z., Jin, T., Wu, B. and Ding, F. Condition based maintenance optimization for wind power generation systems under continuous monitoring, Renewable Energy 2011, 36, 1502-1509

21. Kovacs, A., Erdos, G., Viharos, Z.J. and Monostori, L. A system for the detailed scheduling of wind farm maintenance, CIRP Annals-Manufacturing Technology 2011, $60,497-501$.

22. Chang, T.J., Wu, Y.T., Hsu, H.Y., Chu, C.R. and Liao, C.M. Assessment of wind characteristics and wind turbine characteristics in Taiwan, Renewable Energy 2003, $28,851-871$.

23. Andrews, J.D. and Moss, T.R. Reliability and Risk Assessment, $2^{\text {nd }}$ edition, Professional Engineering Publishing Ltd: London, 2002 